\title{
NEW WORLD
}

\section{Bleak Record of International Collaboration}

ONE of the chief advocates of closer international collaboration in space research, Dr Thomas Paine, the director of NASA, had a sad tale to tell the Senate Committee on Aeronautical and Space Sciences last week about his agency's efforts to collaborate with others elsewhere. The most sombre part of his tale was the record of attempts at collaboration with the Soviet Union. He said that first attempts to cooperate in planning go back to the preparations for the International Geophysical Year in 1955, but that even then "agreements for exchange were held to a minimal or token level. The Soviet side has not fully complied even with these". Efforts at cooperation by the United States in 1959 are said to have come to nothing, and Dr Paine says that he considers "disappointing", the outcome of the agreement between the Soviet Union and the United States of June 1962 which allowed for the coordinated launching of experimental weather satellites and the exchange of such data as might result, the coordinated launching of Earth satellites equipped with absolute magnetometers and the use of communications satellites for joint experiments. This agrecment was followed by one in November 1965 which would have produced a collaborative review of "space biology and medicine". Dr Paine explained that although the communications channels between Washington and Moscow intended for the exchange of meteorological data were established in October 1964, Russian transmissions of satellites as distinct from conventional weather data had not been "operationally uscful". In the same spirit, he said that the Soviet Union has not yet said which of the data from the second of the orbiting geophysical observatories it wishes to receive, and that the exchange so far had been restricted to ground based data in an irregular fashion. The experiments with communications satellites may not be a good test of good will, for they were intended to be built around the Echo II satellitc, but Dr Paine said that the Russians did provide reasonable data about radio reception even though they declined to transmit; a part of the difficulty with this experiment seems to hare been at Jodrell Bank. The plan to produce a joint review of space biology, on the other hand, seems to have been frustrated by difficulties with correspondence.

Dr Paine gave a detailed account of the attempts that have been made to extend the collaboration between the United States and the Soviet Union in space research (see panel). In the past six months, according to this list, several invitations by NASA to the Soviet Union to collaborate in American space ventures have been rebuffed or ignored, although on December 12, 1969, Academician Keldysh, the president of the Academy of Sciences of the USSR, agreed that there should be a meeting "in three or four months" to discuss the further development of collaboration between the two countries while at the same time declining an invitation to mount Russian experiments in American interplanetary rockets.
Another thorn in Dr Paine's flesh seems to be the reluctance of the Russian authoritics to provide more than "generalized assurances" that Russian rockets to other planets or to the Moon are in fact sterilized so as to prevent contamination. But Dr Paine seems to be a realist about this and accepts that collaboration with the Soviet Union "is not limited so much by technical considerations as by political considerations on the Soviet side", so that there is little prospect that the Russians will accept substantial proposals even though "we do not propose to stop trying".

Elsewhere, according to Dr Paine's account last week, collaboration has been more successful, even in comparatively humdrum fields such as the development of vertical and short range take-off aireraft, in which Canadian, French, German and British teams are involved. Dr Paine singled out the proposal for the German-American solar probe, towards which the West German government will contribute the greater share of the cost-more than $\$ 100$ million altogether. There has been particular interest in collaboration on the space shuttle. According to Dr Paine, the principles of these agreements are that NASA should enter "only into concrete, carefully defined projects of clear mutual interest" and that the partners in the collaborative schemes should pay for their own responsibilitics. Last October, 43 foreign governments as well as ELDO were given an ontline of the plan for the space shuttle. Last week, ESRO, ELDO, the European Space Conference and a number of other governments were represented at a quarterly review of the development of the proposed space station. Similar meetings will follow later this year. Clearly, however, the degreo to which these countries will participate, which Dr Paine says "depends on decisions that only they can make", is limited not merely by the novelty of the exercise but by the fact that countries other than the United States and the Soviet Union spend only about $\$ 300$ million a year on space.

The difficulties are not merely financial. A spokesman for NASA said that the administration had been anxious not to lay down in advance the principles on which collaboration in new rentures should be based, but considered it was for "third" countries to make proposals themselves. 'The governments concerned are however at a loss to know how the kinds of contribution they might be able to make could win anything but a nominal part in ventures such as the space shuttle. As things arc, where bilateral agreement to cooperate involves an American launching of, say, a French satellite, the French will pay for and build the satellite and NASA will provide the rocket on the understanding that information is equally shared. Where some practical use for the satellite is foreseen, as with the launching of telecommunications satellites for Intelsat, the manager of Intelsat (Comsat) will reckon to pay not merely for the satellite (which it contracts for directly) but for the direct cost of launching and something towards research and development. 